\title{
Research on the Perfection of Economics and Management Experiment Teaching Based on New Information Technology
}

\author{
Hongwei Wang ${ }^{a}$, Xiaojun Lu ${ }^{b, *}$ \\ Harbin University of Commerce, Harbin, China \\ awhwdsh@126.com, lxjharbin@126.com
}

Keywords: cloud computing; big data; economic management; experimental teaching

\begin{abstract}
The experimental teaching of economics and management is getting more and more attention, but there are many problems in the construction of experimental platform, teaching resource management and teaching quality evaluation. Exploring the experimental teaching mode of economics and management in the new situation, accelerating the construction of experimental teaching and management, and improving the quality of experimental teaching are the key issues to be solved in the experimental teaching process. The development and maturity of information technology such as "cloud computing" and "big data” provides a feasible solution for solving the needs of economics and experimental teaching.
\end{abstract}

The experimental teaching of economics and management is an important means to consolidate students' professional theoretical knowledge, exercise students' practical ability and cultivate students' comprehensive quality. In order to comprehensively promote the informatization of education and improve the education and teaching quality of colleges and universities by means of information technology, the Ministry of Education and the education administration departments of various provinces have successively issued a series of guiding documents, clearly proposing "to vigorously strengthen the practical teaching of colleges and universities and effectively improve the society of college students." In August 2013, the Ministry of Education issued the "Notice on the Construction of a National Virtual Simulation Experimental Teaching Center" in this context, in addition to the requirements of "practical ability" and "practical teaching as the core indicators in the evaluation of teaching work in colleges and universities". Various economics and management colleges have actively built economic and management laboratories, and the experimental teaching of the management has been rapidly developed and achieved remarkable results, which has played a certain role in cultivating the practical innovation ability of economics and management students. However, the current experimental teaching of economics and management in higher education institutions still has problems such as single function of experimental platform, inability to share teaching resources, lack of quantitative analysis of experimental results and quality, and traditional experimental teaching methods can no longer meet the needs of training professionals in economics and management.

\section{Current status of experimental teaching}

\subsection{Lack of overall planning, repeated construction is serious}

In the process of building a laboratory, various economics and management colleges generally lack overall planning, and do not effectively utilize the experimental resources already existing in various disciplines. These specialized self-built laboratories are generally small in scale, simple in function, and experimental resources. Single, only to meet the development of a single experimental teaching of students in this major, can not provide support for other professional experimental teaching, repeated construction, the phenomenon of resource waste is more serious. 


\subsection{Teaching resources need to be improved}

The construction of teaching laboratories, whether it is hardware teaching facilities or software teaching resources, requires more funds. Many schools and colleges are restricted by the funds for running schools. The scale of the laboratory is small, the equipment is updated slowly, and the failure rate is high. It cannot meet the rapid development needs of the experimental teaching of the management. The purchased teaching software resources lack funds for upgrading and maintenance. Outdated, students are unable to keep up-to-date on the knowledge updates of relevant management majors such as accounting and taxation.

\subsection{Laboratory maintenance difficulties}

At present, there are many management and training software projects, and these softwares are provided by different software vendors. The software has differences in data environment and software architecture. The compatibility between software is poor. It often happens during software installation and operation. Conflicts, poor running results, and difficult software upgrades have led to a large amount of routine maintenance work in the laboratory, which has increased the maintenance difficulty of laboratory staff.

\subsection{Experimental teaching resource utilization is low}

A common solution for the construction of laboratories and labs is to set up a computer room with the function of intra-campus LAN, and install various professional experiments and training software on the server for the students of the management to carry out experimental teaching activities. This program requires students to use a variety of teaching resources only by accessing computers in the campus network during the open hours of the lab. Once the lab is closed or not within the campus network, the system cannot be logged into the system. Students who use mobile data terminals to conduct experimental projects in their spare time cannot be implemented, and teachers are unable to provide guidance to students at any time.

\subsection{The lack of scientific and accurate analysis of experimental teaching results}

In the process of conducting experimental teaching in the economics and management colleges, it is often after the determination of a certain experimental project, the students are organized to carry out the teaching work according to the requirements of the project, and the corresponding experimental results are given according to the experimental results. For students in the experimental project which methods are reasonable, which methods are wrong, whether the teaching plan is reasonable, how to improve, in the face of a large amount of experimental data, the instructor is completely unable to do so, in most cases can only be based on subjective judgment Some even did not conduct inductive analysis, and simply taught to complete the teaching. Lack of analysis of experimental results and effects deviates from the essence of the experimental teaching of the experiment, and can not achieve the goal of experimental teaching, which only causes waste of resources.

\section{Innovation and practice of construction simulation and simulation laboratory under the condition of new information technology}

\subsection{Vigorously develop the construction of cloud environment management experiment teaching platform}

Cloud computing is a business computing model. It distributes computing tasks across resource pools of large numbers of computers, enabling applications to acquire computing power, storage space, and information services as needed. Cloud computing accesses servers, storage spaces, databases, and various application services over the Internet in a simple way. Users can access cloud computing service providers through browsers at any time, anywhere, with a variety of mobile devices. A large amount of data storage resources provided. Cloud computing is called the fourth 
wave after the mainframe, personal computer, and the Internet. After nearly a decade of rapid development, cloud computing technology has matured. Because cloud computing can effectively be compatible with heterogeneous hardware and software infrastructure resources, it is possible to integrate different software vendors, various architecture-based experiments and training projects of different architectures, and utilize virtualization, resource pools, multi-tenancy, and data migration. And other cloud computing technologies, build resource virtual pools and storage pools, and provide flexible and personalized application services for economics and management students of different professions and different teaching tasks in a virtualized environment to meet the needs of economics and experimental teaching. Through the experimental teaching cloud platform, teaching resources can also be shared among institutions.

The construction of the experimental teaching cloud platform should avoid the phenomenon of re-emergence and repeated construction. The Ministry of Education and the provincial education management departments should formulate normative documents for the management of experimental experiments on the basis of guiding documents, rational planning and unified standards. The macro management level promotes the construction of cloud resources for experimental experiment teaching.

\subsection{Establishing a management experiment analysis system for economics and management under the support of big data}

With the rapid development of networking and information, everything can be digitized. People's perception of traditional data has been completely changed after the emergence of big data. The acquisition, storage, analysis, mining and visualization of data Major changes have made people unable to do anything in the face of massively structured, semi-structured, unstructured data. Under the background of big data, the experimental teaching of various majors in economics and management should be given more full attention, and a data-centered experimental teaching analysis system should be constructed. In the experimental teaching of economics and management, big data technology can be cited to store, organize and analyze the data obtained during the experimental teaching process. Through quantitative analysis of data, judge the quality of teaching, teaching effects, accurately grasp the rules of experimental teaching, timely adjust and improve the existing teaching methods, formulate reasonable experimental teaching plans, and improve the quality of experimental teaching. With big data analysis, it is possible to judge different management subjects, even different individual students, and to learn interest and mastery of different experimental contents or different knowledge points of the same experiment, so as to target learning objectives of different professions and individuals. The content of the study will be adjusted to develop a more personalized and comprehensive talent training program.

\subsection{Improve the construction of management teaching management system for economic management}

The experimental teaching platform is the core part of the experimental teaching of the management class. However, it is not enough to rely solely on the experimental teaching platform in the experimental teaching process of the economic management class. The construction of the experimental teaching management system should be gradually improved. The complete economic management teaching management system should be supported by cloud computing and big data, covering the experimental teaching platform, experimental quality analysis platform, practical training platform, entrepreneurial innovation platform, experimental research platform, school-enterprise cooperation platform and other subsystems. Through the cooperation of these subsystems, the integration of production, education and research is realized, and the important role of experimental teaching in the training of management personnel is better played. 


\section{Conclusion}

The core of promoting education informatization lies in the organic integration of education, teaching and information technology, and the use of information technology as a means to promote the improvement of education and teaching quality. Applying information technology such as cloud computing and big data to the experimental teaching of economics and management provides technical support and guarantee for the experimental teaching of economics and management. It is of great significance for improving the level of experimental teaching, improving the quality of experimental teaching, and deepening the reform of experimental teaching.

\section{Acknowledgements}

This project is supported by the practical teaching reform and research project of Harbin Commercial University in 2018 (subject name: mobile laboratory design and construction and application) and the higher education teaching reform research project of Heilongjiang Education Department in 2018 (subject name: mobile laboratory design and construction and application).

\section{References}

[1] Zheng Hengbin. Research on the Construction of Economics and Management Laboratory in Local Universities Based on Cloud Computing [J].Higher Education Online, 2018(04):153

[2] Wen Congyuan. Using the cloud technology to build an advanced economic management experiment teaching support environment [J]. China Education Information, 2014 (01): $74-77$

[3] Xue Yongji, Chen Jiancheng, Wang Mingyuan. Exploration and Practice of Virtual Simulation Experiment Teaching in Economics and Management Majors [J].Laboratory Research and Exploration, 2017(10):283-286

[4] Zhang Gaosheng. Innovation and Practice of Construction Simulation and Simulation Laboratory under the Condition of New Information Technology [J].Accounting Education, 2016(09):112-114

[5] Leng Xufeng. Research and Design of Economics Experimental Teaching Platform under Cloud Environment [J]. Enterprise Herald, 2016(11): 117-118

[6] Yang Jin, Lu Yumei. Construction of Integrated Management Platform for Economics and Experiments in Cloud Environment [J].Experimental Technology and Management, 2016(08): 119-122

[7] Lei Huaiying, Wu Yingming. Discussion on Quantitative Analysis Experiment Teaching of Economic Management Majors under the Background of Big Data[J].Journal of Shanxi Economic Management Cadre College,2017(09):110-116

[8] Wang Fang, Yang Lei, Guo Huiting, Ji Jingying. Exploration on the Reform of Economics and Experiments Experiment Teaching under the Background of Big Data [J].Lab Science, 2016(06):72-75

[9] Wang Kai. Research on the countermeasures of experimental teaching of economics and management in the era of big data [J]. Journal of Hubei University of Technology, 2017(03): 72-75

[10] Tao Lin. Reform of Economics and Management Experiment Teaching in the Age of Big Data [J]. Rural Economy and Technology, 2018(01): 282-284

[11] Wang Xiaolei, Liu Haining. On the Importance of Data Science Applied in Experimental Teaching of Economics and Management [J].Experimental Technology and Management, 2016(04): 179-181 